\title{
The Effectiveness of Using SCAMMEER Strategy in Developing English Critical Reading Skills for First Year Secondary School Students
}

\section{Marwa Abdelsabour Mahfouz}

MA Candidate, October 6 University

\section{Abstract}

7 he current study attempts to investigate the
effectiveness of SCAMPER strategy in
developing secondary school students EFL critical reading skills. The current study is a quasiexperimental pre-post one group design. The study participants were (22) first year secondary school students. To collect the data, a three-unit instruction reading comprehension program was designed. Before the treatment, the participants' critical reading skills were pretested. During the course of intervention. After the study group exposed to explicit SCAMPER strategy. Results revealed that the study group mean scores on the post critical reading test surpassed that of the post-test. Accordingly, SCAMPER strategy was effective in developing EFL secondary school students' critical reading. However, teaching English critical reading should be an integral part of EFL secondary school curriculum.

Keywords: SCAMPER Strategy, Critical Reading.

\section{Introduction}

Over the past decades, traditional education has focused on the basics of reading, writing and arithmetic, these skills may be successful for a time other than this time. Today, and with a growing pace of changes leading the world, the need for different skills from those of the past has appeared. Skills such as creativity, innovation, problem solving and critical thinking have emerged. In the light of these overall changes in various life fields, society has become in a need for people who are able to make unconventional decisions, able to think and see the familiar in an unfamiliar way, and distance from stereotypes. The field of education is not 
isolated from these changes, as the modern theories of education focus on motivating the learner to selflearning, and consider the learner as the main focus of the educational process. Following the latest strategies and methods of teaching to achieve the desired objectives of the teaching and learning processes to meet the needs of the society in the light of global changes and trends.

In the current era of accelerating development, and in the light of the growing of knowledge and the development of education and learning, which emphasizes the importance of quality and effectiveness of education, and work to develop the skills of creative thinking of students, this created great challenges for the school and teachers, so it was necessary to provide students with what they need through following the latest strategies and methods of teaching. In this regard, several studies have emerged, which shed light on the importance of using teaching and learning strategies in line with the successive and upcoming changes in society. Hani (2013) explained that the modern teaching trends in the world are rapidly moving towards paying attention on the learners, and developing their abilities of thinking to be effective. This can be achieved by encouraging students to investigate, solve problems, brainstorm and raise questions, apply what they have learned, and use strategies and methods that seek to stimulate thinking and develop students ' self-learning skills. As a result, the role of the teacher in the current age needs to keep the pace of developments in the field of curriculum and teaching methods, and even devise methods and strategies that suit the educational situation and the characteristics of learners so as to give them the 
opportunity of using knowledge and skills acquired in the attitudes of life (Ibrahim, Falah \& Reilly 2006).

In this regard, there was a need to use modern, innovative approaches and strategies to develop critical reading skills in English. The SCAMPER strategy is one of the latest proposed strategies for teaching and learning critical reading skills. This strategy is characterized by its ability to motivate students creative thinking skills by employing a list to generate ideas. As for the strategy of SCAMPER as a modern strategy used in the development of critical reading skills, Melvira (2012) explains that the SCAMPER strategy has proven to be effective at the level of many subjects, and is one of the active strategies that can be applied by the teacher in teaching English language skills. To apply SCAMPER strategy effectively in educational settings, teachers should follow a number of key actions and steps, including that the teacher should prepare the lesson plan to be able to prioritize and identify the mechanisms through which the information will be transferred to Students. Then, choose the most interesting topics to keep students attention as long as possible. Also, the teacher will manage the time needed to apply that strategy, which includes the time of explaining and time of students individual and group work in a collaborative manner.

According to Al-Hosainy (2013) SCAMPER strategy is a teaching strategy based on a range of emotional processes such as curiosity, complexity, intuition, and cognitive processes such as: fluency, flexibility, and originality. Several studies have illustrated the effectiveness of the SCAMPER strategy in generating ideas. In this respect, the study of Toraman and Altun (2013) has shown that SCAMPER strategy is one of the 
strategies through which the levels of creativity among students can be enhanced. A number of questions are directed to learners in a way that encourages them to get out of the ordinary, and to think in a non- traditional way, as these questions are the driving force that allows them to gain many various thinking skills which can improve the quality of thinking and encourage discovery as well as thinking more flexibly. According to Hani (2013) the strategy of SCAMPER is defined as a descriptive word describing the process of searching for new ideas and generating them cheerfully.

The word of SCAMPER consists of the initials of a set of words that form the whole word SCAMPER and these words form the list of ideas generated by Ebrel (2008) as follows: Substitution (Substitute), which is denoted by the letter S: Things that can be replaced in any text or problem of another person's role, what can be exchanged or what can be used as an alternative? And then put an alternative to an idea or action or anything else, such as replacing a character personality in the story, or replacing an event with another, or replacing a cause or a result by another/and the merger (Combine) which is denoted by the letter C: merging or mixing ideas with each other means: to add an idea. For example: Merging ideas or goals, and reformatting or shaping some things. Adaptation (Adapt / Adjust) denoted by the letter A: it is intended to modify an idea or suggestion to suit the desired objective. For example, new ideas that can be suggested, change the shape, rearrange or change the story events or generate new ideas to solve the problem. Change ( Modify) , (Magnify) or Minimize (Minify) and denoted by the letter M: Change the shape or type by making adjustments by resizing, shape, or color, for example: Change the 
meaning, change ideas for the better, such as minimizing or enlarging the main or secondary characters in the story, or expanding an idea in the essay writing. Use for other purposes (put to other uses) and is denoted by the letter P: it means using different objectives than the original target. For example: What are the new uses of an idea? / What can be done with this idea? Deletion (Eliminate) is denoted by the letter $\mathrm{E}$ : the deletion or minimization of some parts of the piece of writing, e.g. deletion of a word from a sentence, deletion of a paragraph from text, deletion of ineffective events or ineffective ideas. Reverse or reorder (Rearrange/Reverse) is denoted by the letter $\mathrm{R}$ : The order of ideas in other forms, such as: reshaping or altering the components of an idea or the other, and making another arrangement of the notion, changing the end or reversing or changing the sequence of events or ideas, considering the related changes within the text as a result. SCAMPER strategy is considered as one of the strategies of ideas generating and regarded as an extension of the ideas and recommendations made by Alex Osborne, for the generation of thoughts, effort or brainstorming while doing a process of thinking.

According to Blessing, Yang and Wood (2014) SCAMPER is one of the strategies that can be used to enhance the thinking process and the principles on which ideas are generated and expressed. SCAMPER strategy is based on the premise that innovation and creativity stem from critical thinking, arrangement and addition of new ideas. Actually, all elements of the SCAMPER strategy can be applied while reading a text critically to go beyond the superficial meaning. As for the role of the teacher and the learner, in the application of the SCAMPER strategy within the English 
language classes, the teacher should present the strategy and explain the list of generating ideas to students. While using SCAMPER strategy in the class, the teacher is a guide, advisor and learning facilitator. Teacher orients student to individual and group work, ideas produced by the nature of the lesson, and time management to provide students with appropriate training opportunities to use the SCAMPER scheme during the application to generate ideas, and the teacher plays a key role in the process of evaluation. The teacher encourages students to apply the SCAMPER strategy after reading a text for comprehension, to answer the questions critically. The role of the student is reflected in the application of the SCAMPER strategy list to show deep understanding of ideas, expressions and thoughts clearly.

Language is considered as a mirror of society. It is a means of communicating among people, to express the feelings, thoughts, opinions and problems of the human beings. Language creates a state of common understanding among members of society, and it is considered part of its cultural heritage. Reading is a basic life skill. It is an essential skill for a child's success in school and in the daily life. Reading is a means of language acquisition, communication, and sharing ideas and information. It is a complex interaction between the text and the reader which is shaped by the reader's prior knowledge. In this respect, reading skill requires continuous practice and development. Critical reading is a high level of reading. Through critical reading students understand each other's ideas, emotions and imagination. So, it requires to show creativity in understanding beyond the lines. Critical reading skills indicates some features such as analyzing and planning. 
There are indications that the practice of creative behavior in linguistic performance requires the existence of contexts, contents, and attitudes which are capable of moving the intellectual abilities of individuals in order to invent thoughts. Explains the benefits of developing students' creativity within the English language classes (i.e. the development of students ' different mental skills, such as questioning ,imagination, and the development of cognitive skills which include evaluation and meditation) as they increase student motivation and positive participation in language learning and give students the ability to think flexibly ( Patricia 2011).

\section{Context of the Problem}

The researcher felt the problem of this research through her experience as an English language teacher for 14 years and through the direct observation of her students. Also, noted through academic supervision since 2014 until now, and also through follow-up students' achievement in reading skills. The researcher observed that there is a lack of critical reading skills among first-year secondary school students. The researcher attributed this to the lack of use of English language teachers to modern strategies that keep pace with continuous changes in education field to develop the critical reading skills of students in English language.

\section{Statement of the problem}

The problem of the study is represented in lack of critical reading skills first-year secondary school students. The researcher attributed this to the lack of use of English language teachers of the modern teaching approaches and strategies to develop their students' critical reading skills. In an attempt to solve 
this problem, the research uses SCAMPER strategy to develop critical reading Skills in English for students of the first secondary grade.

\section{Questions of the Study}

Based on the study objectives, the current study attempts to answer the following questions:

1. What are the required English critical reading skills needed for first -year secondary school students at Al-Azhar female secondary school in Sedfa, Assuit governorate?

2. What is the effectiveness of SCAMPER in development critical reading skills in English for first-year secondary students?

\section{Hypothesis of the study}

The study aimed at testing the following hypothesis

1. There is a statistically significant difference between the mean scores of the study group on the pre and post administration of critical reading test first skill (S: Substitute a person, place, time, idea, mood or situation / What do you think would have happened if the father bear was a mad man instead of being a kind bear and treated the girl in a bad way? ) in favor of the post administration of the test.

2. There is a statistically significant difference between the mean scores of the study group on the pre and post administration of critical reading test second skill (C: Combine, bring together assorted ideas and situations/ What would have happened if the three bears were returning from a reunion with relatives who had escaped from a zoo where they had been badly treated by the zookeepers?) in favor of the post administration of the test.

3. There is a statistically significant difference between 
the mean scores of the study group on the pre and post administration of critical reading test third skill (A: Adapt or adjust ideas or information to suit a purpose / How might the story have changed if Goldilocks had been lost in a city instead of the forest?) in favor of the post administration of the test.

4. There is a statistically significant difference between the mean scores of the study group on the pre and post administration of critical reading test fourth skill (M: Modify for example, by changing the physical size or personality traits of some characters or changing the setting or ideas/ What would have happened if the bears had been police bears and much smaller than Goldilocks?) in favor of the post administration of the test.

5. There is a statistically significant difference between the mean scores of the study group on the pre and post administration of critical reading test fifth skill (P: Put to other uses, for example, put a different slant on the plot/ What if Goldilocks was only pretending to be lost and was really looking for an excuse to break into other people's houses?) in favor of the post administration of the test.

\section{Objectives of the Study}

In general, the present study aims at investigating the effectiveness of SCAMPER strategy in EFL critical reading instruction to manage critical reading difficulties and problems encountered by first-year secondary students. This involves accomplishing the following two objectives:

1. Developing critical reading skills required in English for first -grade secondary school students.

2. Identifying the effectiveness of SCAMPER strategy 
to develop critical reading skills in English for firstgrade students.

\section{Significance of the Study}

The significance of the present study stems from the following points:

1. The study was expected to use SCAMPER strategy to improve first-year secondary school students' critical reading skills.

2. It enriches the educational field by shedding light on modern approaches that can be used in the development of different English language skills and other subjects.

3. Results of the study might be used in Continuous Professional Development (CPD).

4. It might improve students' critical reading skills which may contribute to students' academic achievement and develop critical reading skills.

5. It offers a critical reading test that process the language learning assessment .It provides teacher with a systematic procedure to help students with different abilities to learn the strategies that they need for reading critically.

6. Students involved in this study were expected to change their attitudes towards critical reading and to have higher critical reading skills and generating ideas.

7. The finding of the present study might be both theoretically and practically significant for EFL curriculum designers, researchers, textbook developers, language planners, teachers as well as learners and their parents. 


\section{Definition of Terms}

\section{SCAMPER}

The SCAMPER strategy, according to Hani (2013), is a descriptive word that describes the process of searching for and generating new ideas. The term "SCAMPER" means "run". SCAMPER consists of a group of words that collectively comprise the word SCAMPER. SCAMPER strategy is defined as a teaching strategy based on a range of emotional processes such as curiosity, risk tolerance, complexity, intuition, and cognitive processes such as: fluency, flexibility, and originality (Al-Hosainy, 2013).The procedural definition of SCAMPER strategy is defined as a set of teaching steps where each letter corresponds to an abbreviation of a particular meaning $S$ (substitute) ,C ( combine ) ,A (adapt/adjust) , M(modify/magnify/ minify ) ,P (put to another use ) , E ( eliminate ) and $\mathrm{R}$ (rearrange, reverser ).

\section{Critical Reading}

According to Axelrod, Cooper and Warriner ( 2008) Critical reading means that a reader applies some processes, models, questions, and theories that result in enhanced clarity and comprehension. The reader is more involved, both in effort and understanding, in a critical reading than in a mere "skimming" of the text. A critical reading gets at "deep structure", that is, logical consistency, tone, organization, and a number of other very important sounding criteria. According to this research, critical reading is defined as reading for implied meanings with critical evaluation. The act of critical reading goes beyond the literal comprehension of the texts to demand the reader produces original ideas not explicitly stated in the reading texts. 


\section{Study Delimitations}

The current study is limited:

1. Develop critical reading skills in English for firstgrade secondary students.

2. Use SCAMPER strategy to develop some critical reading skills and sub- skills in English for first-grade secondary school students.

3. Adopt a random sample of female students in the first-year secondary in one of the schools located in Assiut governorate where the researcher resides during the academic year 2018/2019.

4. Use the English language textbook of first secondary grade, along with an enrichment module of the curriculum for teaching critical reading.

5. Application of the quasi-experimental approach known as the design of the pre- test and the posttest on the study group, to which the SCAMPER strategy applied.

\section{Review of Literature}

Reading has been the focus of various studies for the past few decades According to Wallace and Warry (2011) reading is a complex activity that involves both perception and thought which allows the readers to analyze a certain message to get information from a text. According to Duncan (2004) reading is an activity that requires both skill and cognitive ability used to understand messages included in the texts. However, Critical reading is a more active way of reading. According to Azennoud ( 2013 ) Critical reading, as an advance skill, is the ability to understand the text and the given information then anatomize how it is presented, get the purpose of the writer beyond the ideas and determine the perspective, improve what it means, and apply it. This ability to read critically is a 
process, so the reader has to master essential techniques that lead him to be a good critical reader through some of mental processes. The study of Milan (2006) states that critical reading is not simply close and careful reading. That to read critically, the reader has to recognize and analyze actively the evidence upon the page. Several studies emphasized the vital effect of teaching critical reading skills. Critical reading involves highly complex cognitive processing operations and needs creative way of teaching. The aim of reading in any language is considered to have access to the literature written in that language. In language teaching, reading texts have traditionally been chosen from literary texts which represent "higher" forms of culture. According to Axelrod, Cooper and Warriner (2008), critical reading means that a reader applies certain processes, models, questions, and theories that result in clarity and comprehension. The reader is actively involved, both in effort and understanding, in reading critically than in a mere "skimming" of the text. If a reader merely "skims" the text, superficial characteristics and information are as far as the reader goes. Critical reading happens at "deep structure", which is, a number of other very important sounding terms such as logical consistency, tone and organization. Critical reading requires a learner to not only consider the information represented in a text but also the meaning behind the Writer's expressions. Critical reading teaches students to analyze and question what they have read and to match it to their understanding of the subject matter in relation to other things they may have read. By this, students are engaged in active communication with the author. These requirements to actively engage with subject matter are at the heart of higher order thinking and are 
at odds with the drill and memorize routine that turns so many students away from education. The study of Barnet, Bedau and O'Hara (2008) clarified that critical reading can be distinguished from critical thinking as critical reading is a technique for discovering information and analyzing ideas within a text. Critical reading gives the reader the opportunity to judge the author's ideas, analyze them, agree/disagree, evaluate and suggest alternative.

On the other hand, critical thinking is a technique for evaluating information and ideas, for deciding what to accept and believe. In this respect, critical reading refers to a careful, active, reflective, analytic reading, while critical thinking involves reflecting on the validity of what you have read in light of our prior knowledge and understanding of the world. By these definitions, critical reading would appear a reflection to critical thinking. Stepanek (2010) and Richards (2013) studies emphasized that curriculum designers should provide opportunities for teachers to create creative abilities for their students such as flexibility, critical thinking. The studies recommended that English teachers use modern methods and strategies to develop the creative aspects of students and high order of thinking. That the acquisition of knowledge requires more than regular reading ability that critical reading increases the skills of critical thinking deep reader comprehension.

Al-Harithi (2015) aimed at recognizing the impact of using SCAMPER strategy in developing the vocabulary of English language by investigating the impact of the strategy on students' use of the English vocabulary. The results of several studies, such as the studies of Abu Seif and Moqabla (2016) and Abu Laban (2013) confirmed the effectiveness SCAMPER strategy 
in developing the skill of writing in Arabic language. The study of Hani (2013) used SCAMPER strategy to improve students' achievement in science of the fourthgrade students. SCAMPER strategy proved its effectiveness in development of thinking skills in the generating ideas in science subject. Other studies in TEFL such the studies of Buser, Gladding and Wilkerso( 2011) , Edek (2016 )and Ozyaprak (2016) used SCAMPER strategy to enhance the student's creativity in the field of coaching.

Based on the above, it is clear that the use of the SCAMPER strategy for first- year secondary school students in English language classes can be beneficial to improve their language skills, especially in the development of critical reading skills. The researcher also regards critical thinking as an essential component of critical reading which students can acquire through the application of appropriate learning strategies such as SCAMPER strategy for differentiated students' levels.

\section{Method}

\subsection{Participants}

The study group included twenty-two first year Secondary school students at Al- Azhar Secondary Institute in Sedfa, Assuit governorate to be the experimental group. The students' ages ranged from 15-16 years old. This group was chosen for the following reasons. First, they were in need to master some critical reading skills as a base to follow up their progress of learning. Second, the results of the pre-test indicates students' deficiency in critical reading skills. Third, it was appeared from the informal interviews with some English teachers that the teaching of critical reading in the current form does not provide students with opportunities to think and express their ideas to 
reach the stage of reading critically in English. Besides, Many English teachers do not care about the development of critical reading skills among students. They choose limited traditional comprehension text, focusing on superficial understating of the ideas, and neglecting aspects of critical thinking.

\subsection{The Experimental Design}

The current study followed a quasi-experimental pre-post one group design. This design was chosen to evaluate the influence of the teaching strategy on 1st year secondary school students by comparing the performance before and after applying the teaching strategy. The design of the present study can be presented by the following patterns: A1-----X------A2.

\subsubsection{Research Design}

\begin{tabular}{|l|l|l|l|}
\hline Group Type & Pre-test (A 1) & Treatment (x) & Post-test (A2) \\
\hline $\begin{array}{l}\text { Quasi- } \\
\text { experiment } \\
\text { al }\end{array}$ & $\begin{array}{l}\text { Critical } \\
\text { Reading } \\
\text { skills test }\end{array}$ & $\begin{array}{l}\text { SCAMPER } \\
\text { Strategy }\end{array}$ & $\begin{array}{l}\text { Critical } \\
\text { Reading } \\
\text { skills test }\end{array}$ \\
\hline
\end{tabular}

Through this design. The researcher investigates the difference between pre-post test scores (A1 and A2) regarding the effect of the treatment $X$. The researcher used the quasi-experimental method as the main research design that will guide the treatment evaluation because it has proven its effectiveness as a scientific and experimental research design to ensure the existence of a scientific basis for the evaluation of the teaching strategy. Besides, the researcher adopted the quasi-experimental design because this kind of designs is more common in educational research. It aimed at determining the effectiveness of the independent variable on the dependent variable referring to its validity by causing positive change on students' performance (Shadish \& Cook ,2002). 


\subsection{Research Instruments}

The researcher used the instruments that help to answer the research questions; these instruments increased the validity of the research and reduced bias. To fulfill the research objectives, the following instruments were prepared by the researcher.

1. A critical reading Pre-Post Test to assess critical reading skills

2. SCAMPER Strategy framework which consists of:

a. A student's handbook b. Lesson Plan

The study was designed for 1st year secondary school students; this study is based on using SCAMPER Strategy to develop EFL critical reading skills. The experiment was carried out during the second term of the academic year 2018/2019. It lasted for two weeks; a period every day from 6th April until 18th April. The whole content (Three Units) was taught for 12 periods.

\subsubsection{Critical Reading Test}

\subsubsection{Objectives of the test}

The proposed study mainly aims at applying SCAMPER strategy in EFL critical reading instruction to manage critical reading difficulties and problems encountered by first-year secondary school students. This involves accomplishing the following three objectives:

1. Develop critical reading skills required in English for first -grade secondary students.

2. Identify the effectiveness of SCAMPER strategy to develop critical reading skills in English for firstgrade students.

3. It adopts a group of critical reading skills and subskills that develop the main features of critical reading. 
The objective of the critical reading pre-posttest is to evaluate the effectiveness of SCAMPER strategy on developing 1st year secondary school students critical reading skills. The pre-posttest is designed to identify (a) the students' performance levels in critical reading skills; and (b) the range of development that could be achieved after administrating the suggested interventional content.

\subsubsection{Content of the test}

The content of the test was prepared in light of the objectives and learning outcomes of the suggested treatment and the main principles of critical reading skills gained from the review of the relevant literature and related studies. The test is consisted of seven questions need to be answered in details and full sentences, covering the key concept of the critical reading skills. The questions test students' abilities of critical reading skills using SCAMPER strategy. The critical reading test included seven items. The items represent the most important and the most emphasized objectives of the program. Test instructions are written in English in a way that makes them brief, easy to understand and free from any possible ambiguity. They represent information about the purpose of the test and time allowed for completing it. The test was designed according to a rubric for assessing the elements of creative writing.

\subsubsection{Validity of the critical Reading test}

Some jury members specialized in TEFL assured the fitness of the suggested program to the study objectives and the learning outcomes. After suggesting few modifications, they agreed on the validity of the content and asserted the appropriateness of the content for 
developing secondary stage students' EFL critical reading skills.

\subsubsection{Administration of the test}

One day before beginning of the treatment, the critical reading pre-test was administered to the participants. After the intervention, critical reading test was re-administered to the same participants as a posttest. Students' mean scores were calculated and compared using t-test.

\subsubsection{Scoring the critical reading test}

The test involved one reading text followed by 7 objective questions. The total score of critical reading test was 70 points where each deserves 10 points.

\subsection{Constructing of the framework of the Study}

The framework of the study is a guidance of what exactly is going on and to ensure that the different aspects of critical reading skills are sufficiently covered .It included the general and specific objectives and learning outcomes, teaching methods and techniques, teaching and learning activities, learning aids and evaluation techniques .It was submitted to some of jury members to judge its validity as for appropriateness of the objectives for the content.

\subsubsection{Constructing Content (student's handbook)}

The content consisted of twelve critical reading lessons; these contents were selected to be used in developing secondary 1st students' critical reading skills and sub-skills. Formative and summative evaluation were used to ensure that the program objectives had been achieved. These criteria were judged by the TEFL jury members to judge its validity .The researcher built up the content according to the following criteria: 
1. Suitability to student's level and abilities.

2. Providing opportunities for more critical reading skills.

3. Appropriateness and appropriateness of the objectives for the content.

4. Appropriateness of the methodology used in teaching of the content.

5. Trainability.

\subsubsection{Validity of the Content}

Some jury members specialized in TEFL assured the fitness of the suggested program to the study objectives. After suggesting few modifications, they agreed on the validity of the content and asserted the appropriateness of the content for developing secondary stage students' EFL critical reading skills.

\section{The experimental Treatment}

1. An orientation session was administrated to help the study group have an idea about the study objectives.

2. Students had the student's handbook to access the course content.

3. The research presented an introduction to help students understand the ideas and concepts of the course.

4. The researcher presented the general and specific objectives of each lesson.

5. Students went through some learning activities after teaching each lesson.

6. For each question students got an immediate feedback about their final scores.

\section{The study procedures}

1. The research undertook the following procedures in achieving the purpose of the study:

2. Considering students' needs (the critical reading 
skills that they need to develop) by administrating some informal interviews with some teachers specialized in TEFL. In addition, building up a list that included some critical reading skills and subskills.

3. Reviewing some literature related to critical reading skills and SCAMPER strategy.

4. Preparing a list of critical reading skills and subskills.

5. Selecting the study group (twenty- two students of 1st year secondary school students).

6. Developing a framework of the study.

7. Ensuring the validity of the framework and the content by the jury members.

8. Constructing the critical reading test and judging the test by the jury members.

9. Starting administrating the experiment.

10.Pre-testing the study group.

11.Administrating the SCAMPER strategy and the suggested content to the study group.

12.Post-testing the study group to evaluate the effect of the SCAMPER strategy.

13. Collecting data and analyzing them by using SPSS.

14. Registering the scores and treating them statically by using statistical treatment.

15.Analyzing the results and making recommendations and suggestions.

\section{Results}

\subsection{Verifying the Hypothesis}

Differences between the mean scores of the experimental group on the Pre and Post Critical reading test. 


\begin{tabular}{|l|c|c|c|c|c|l|}
\hline Group & No & Mean & SD & t & P & Sig. \\
\hline Pre-Experimental & 22 & 12.7727 & 5.3 & 1.16 & 0.001 & $\begin{array}{l}\text { Significa } \\
\text { nt }\end{array}$ \\
\cline { 1 - 4 } Post-Experimental & 22 & 54.3183 & 5.0 & & & \\
\hline
\end{tabular}

\subsection{Discussion of Results}

The previous table displays that the mean scores of the participants of the experimental group on the Postcritical reading test (54.3183) was higher than their mean scores of the Pre- critical reading test (12.7727). When the $t$ value is (1.16) and the P value is less than 0.001 , the difference is statistically significant. Statistically, the hypothesis of the study was accepted as it stated: There is a statistically significant difference between the mean scores of the experimental group participants' mean scores on the pre and post-Critical Reading favoring their mean scores on the post Critical Reading" The increase of the mean scores of the study group on the Post-RCT could be attributed to the effectiveness of the intervention program in developing EFL students' critical reading comprehension. It could be concluded that the proposed program was more effective than regular English classes in developing EFL students 'critical reading comprehension.

\section{Conclusion}

The present study investigated the effect of SCAMPER strategy for developing secondary school students' EFL critical reading skills. Results revealed that the SCAMPER strategy was effective in developing EFL secondary school students' critical reading skills. The mean scores of the posttest is higher than the means score of the pre-test. Accordingly, it could be concluded that SCAMPER strategy contributes positively to EFL language learning. Based on the results from the previous studies, the researcher can get benefit from the present study as follows: 1 . In 
order to overcome students' problems in skills of critical reading in a foreign language, the learners should use SCAMPER strategy. 2. SCAMPER strategy helps students to be more aware of they are reading to go beyond the lines, which enhances their ability to analyze and think critically.3.Applying list of SCAMPER strategy ( Substitute, Combine , Adapt, Modify, Put to other uses ,Eliminate, rearrange or reverse ),makes reading more fun and entertaining as well as it helps students to organize the ideas evaluate them to other writers' ideas. 4. Using SCAMPER strategy enhances skills of critical thinking, creative thinking and evaluation while applying the strategy list. 5. SCAMPER strategy enables learners to be more analytic to what they read. 6. SCAMPER strategy helps teachers to explore the students' awareness and creative aspects. The strategy is recognized as a strategy which facilitates treating ideas critically in an organized and creative way. The findings of the present study might contribute to be a starting point for more future research. Accordingly, more research should be carried out to investigate the effect of SCAMPER strategy on other EFL skills in all different schooling stages. In addition, the findings of the present study have implications for EFL teachers and textbook writers. For EFL teachers, it is advisable that they should enhance students' critical reading skills by using modern and creative strategies. For textbook designers, it is recommended that they include a section in secondary school textbooks that can promote critical reading skills. In this respect, teaching English critical reading should be integrated in EFL secondary school curriculum. More professional development sessions are required to train EFL teachers to better teach critical reading in secondary schools. 


\section{References}

- Abo Saif, A., Moqabla ,N.(2006) .The effect of using Scamper strategy on improving Jordanian female tenth grade students' creative writing skills. AL- Yarmouk University, Jordan .

- Abu Laban, W. (2013).SCAMPER Strategy for developing the skills of creative writing for secondary students. Al-Azhar University.

- Al-Behiri, A (2013) .The effectiveness of web co-operative learning strategy on developing the EFL creative writing skills .Al-Monifia University.

- AL-Harithi, S. (2015) .The Effect of using SCAMPER program on developing English language vocabularies among First Grade Middle School Students in Makkah Al- Mokarramah. UmAlquraa University.

- Al-Hosainy, A . (2013).Developing creative thinking skills by administering "SCAMPER" program. Teachers college, KSA.

- Ali, M. (2009) .The effectiveness of training program based on strategies of developing creative writing skills .Almenya University.

- Allan, K. (2003).Critical thinking thoughtful writing: rhetoric with reading. First Edition. New York, USA: Houghton Mifflin Company.

- Al-Morsi ,W. (2016) .The effectiveness of a proposed Program based on SCAMPER strategy for enhancing some skills of literary taste and creative writing on first year secondary stage students. ASEP.

- Al-Selmi, F. (2010) .The effectiveness of a proposed strategy based on self-organized learning to develop creative writing skills for First Grade Middle School Students. Um-Alquraa University.

- Axelrod,R., Cooper,C \& Warriner,A. ( 2008). Reading critically, writing well. Language Arts \& Disciplines.

- Azennoud, A. (2013).Critical reading skill. Al Akhawayne University, Ifrane.

- Barnet, S., Bedu H \&O'Hara. (2008).Critical Thinking. Reading and Writing 9th Edition, Kindle Edition.

- Blessing, L., Moreno, D., Wood, K. \& Yang, .M. (2014). Analogies 
to Succeed: Applications to Service design Problems. Espoo, Finland, Melbourne, Australia.

- Borges, J. (1994).On writing .2nd Ed. Hopewell, New Jersy .The Ecco Press, USA.

- Buser, K., Buser, J, Gladding. , S \& Wilkerson, J. (2011). The Creative counselor. Using the SCAMPER model in Counselor Training. Journal of Creativity in Mental Health, 6 (4), 256-27.

- Duncan.J. (2004). How to read critically. The riting Centre, University of Toronto at Scarborough.

- Eberle,B.(2008).SCAMPER Creative games and activities. Texas, Press Inc.

- Hani, M. (2013).The effectiveness of SCAMPER strategy in developing generating thinking in science foe grade four students. Dimiat University.

- Ibrahim,S., Falah ,M., Reilly, R.( 2006 ).Creativity and innovation management. Wiley Library.

- Idek, M. (2016).Measuring the application of SCAMPER technique in facilitating creative and critical thinking in composing short stories and poems. Malaysian Journal of Higher Order Thinking Skills in Education, Edition 2/2016.

- Melveria, Y. (2012).Teaching reading of analytic exposition text by using scamper Strategy for senior high school students. e Jurnal Mahasiswa Prodi Pend Bahasa Inggris, 1 (4), 1-6.

- Milan, D. (2006). Developing critical reading skills. Appendix B reading skills.

- Ozyaprak, M. (2016).The effectiveness of SCAMPER technique on creative thinking skills. Journal for Education of Gifted Young, e-ISSN: 2149-360X.

- Patricia, S. (2011).On reading. Harvard University Press Read. C Seven Pillars of Creativity in primary in the English classroom PP.29-36.

- Richards .J. (2013). Creativity in language teaching .English teacher of creativity and discovery in teaching university writing .City University of Hong Kong.

- Shadish, R., Cook, D., \& Campbell, T. (2002). Experimental and quasi-experimental designs for generalized causal inference. Boston, MA, US: Houghton, Mifflin and Company. 
- Stepanker. M. (2010). A creative approach to language teaching: A way to recognize encourage and appreciate students' contribution to languages classes, Maley and $\mathrm{N}$ Peachey, Eds Creativity in the English classroom PP.29-36.

- Temzikan, M. (2011). The Effect of creative writing activities on the story writing skill .Educational Sciences. Theory and Practicaw.

- Toraman, S. \& Altun, S. (2013).Application of the six thinking hats and SCAMPER techniques on the 7th grade course unit .Human and environment: An exemplary case unit study. Mevlana International Journal of Education (MIJE), 3(4), 166-18.

- Waleed, E. (2012). The effect of using reflective teaching in enhancing critical reading Skills in English for 1st grade secondary stage students. Cairo University, Institute of Educational Studies, Curricula \& Instruction Dept.

- Wallace, M \& Warry, A. (2011).Critical reading and writing for postgraduates. Sage Study Skills Publisher 